\title{
Key Considerations in the Recovery and Resumption of Surgical Services after the COVID-19 Pandemic
}

\section{Dear Editor,}

The COVID-19 pandemic has swept across the globe, with 16 million cases and 650,000 deaths to date. ${ }^{1}$ At the peak of the pandemic, countries implemented various measures to avoid overloading their healthcare systems, including the deferment of non-essential healthcare services and surgeries, restructuring the delivery of health services to minimise contact with health facilities, expansion of telemedicine and home care services. ${ }^{2}$ Since Hsu et al. described the challenges and future scenarios for Singapore, ${ }^{3}$ the implementation of a COVID-19 lockdown in Singapore resulted in a further reduction of non-essential healthcare services. It is thus crucial for healthcare systems to establish clear plans for recovery and resumption of services. A sustainable and stepwise approach is necessary, balancing demand and supply, while mitigating the risks of a second wave. Surgeons worldwide face enormous challenges in the recovery process, with the estimated millions of surgeries postponed worldwide. ${ }^{4}$ We discuss 5 key planning considerations in the resumption of surgical services, and propose a 5-phase staged approach:

Aligning to national/regional guidelines. The recovery trajectory of every country and region would be inherently different due to diverse socio-economic and geo-political circumstances. The recovery course would be influenced by a multitude of factors, including the severity of the pandemic, degree of community transmission, COVID-19 testing capability and healthcare resource availability. Hospitals need to constantly keep themselves updated of national guidelines from governmental agencies involved in the COVID-19 response. The operations team in each hospital should then carefully contextualise guidelines and implement them locally. Feedback from hospitals should be regularly provided to the relevant government agencies in order for the latter to evaluate and fine-tune policies. All recovery plans need to consider the broader national and/ or regional guidelines from relevant health authorities.

Adopting a staged approach. A staged recovery process is essential for multiple reasons. It allows the maintenance of 'surge capacity' with minimal pressure on resources, especially important in the early phases of recovery. A staged strategy also allows for the flexibility and ability to rein-in the recovery process in a controlled manner should a second wave of infections occur. Clearly articulated capacity targets and plans for each stage are essential in managing longer term expectations of healthcare staff and patients, and reduce the risk of staff burnout in the long recovery process. ${ }^{5}$

Good resource stewardship. Manpower worldwide has been reduced due to redeployments, with surgical staff deployed to care for COVID-19 patients. ${ }^{2}$ Fragile healthcare systems have been relatively depleted in medical equipment, driven both by consumption and affected global supply chains. Surgical service recovery is intrinsically linked to the management of hospital beds, operating rooms, intensive care units (ICUs) and high dependency beds, and isolation rooms. Recovery plans need to factor in the effects of increased surgical service provision on other interlinked support services for e.g. pathology, radiology, blood supplies, pharmacy and laboratories. A key factor in managing the recovery phase involves good stewardship of precious healthcare resources, and recognising the interdependence of hospital resources.

Prioritisation framework forsurgeries and procedures. The main consequence of deferring surgeries during the COVID-19 pandemic has been an extraordinary build-up of demand for surgeries. ${ }^{4}$ Prioritisation of deferred cases can be guided by guidelines from surgical associations and societies, ${ }^{6}$ or pre-defined scoring systems and prioritisation policies. ${ }^{7}$ Ambulatory and short-stay surgeries can be allowed to resume before inpatient cases to reduce demand for hospital beds. Cases that are significantly resource intensive may need to await further availability of resources before proceeding (e.g. blood transfusions and ICU beds). At each stage of recovery, as more resources are made accessible, surgeons need to prioritise and rationalise the urgency of treatment based on both disease acuity and the degree of resource utilised.

Mitigating the risks of a second wave of infections. As countries ease their lockdowns and travel restrictions, there are global concerns about a second wave of COVID-19 infections. Reducing this risk involves social 
distancing, adhering to scheduled appointment times and screening patients for symptoms. Telemedicine should be continued for eligible patients to reduce unnecessary face-to-face visits. ${ }^{8}$ Patients undergoing surgeries may need to be pre-tested for COVID-19 in accordance to local guidelines, especially vulnerable populations like the elderly, oncology, and transplant patients. ${ }^{9}$ Adequate supplies of personal protective equipment remain essential for workforce protection. ${ }^{10}$ Another key factor in preventing a second wave of infections involves increasing capabilities for COVID-19 tests, early diagnosis, and effective contact tracing. As surgical services resume, surgeons need to guard against contributing to, and being unprepared for, a COVID-19 second wave.
We propose a 5-phase staged recovery of surgical services to allow surgeons to determine which phase they are in at each given time point based on World Health Organization (WHO) transmission classification, local government policy on healthcare provision, degree of social distancing measures, and hospital resource situation. The globally available WHO transmission classification is based on a process of self reporting by countries. They are based on the highest category reported, as differing degrees of transmission may be present within countries. Categories include community transmission, clusters of cases, sporadic cases, and no cases. ${ }^{1}$ If present, local government policies and social distancing measures are also included in describing

Table 1. Five-phased staged recovery of surgical services

\begin{tabular}{|c|c|c|c|c|c|}
\hline & Phase 0 & Phase 1 & Phase 2 & Phase 3 & Phase 4 \\
\hline \multicolumn{6}{|l|}{ WHO transmission classification } \\
\hline $\begin{array}{l}\text { Category based on } \\
\text { COVID-19 situation reports }\end{array}$ & Community transmission & Clusters of cases & Sporadic cases & $\begin{array}{l}\text { Sporadic cases/ } \\
\text { no cases }\end{array}$ & $\begin{array}{l}\text { Sporadic cases/ } \\
\text { no cases }\end{array}$ \\
\hline \multicolumn{6}{|l|}{ Prevailing local conditions } \\
\hline $\begin{array}{l}\text { Social distancing measures (if } \\
\text { applicable) }\end{array}$ & $\begin{array}{l}\text { Lockdown, } \\
\text { social distancing }\end{array}$ & Social distancing & Social distancing & $\begin{array}{l}\text { Social } \\
\text { distancing }\end{array}$ & $\begin{array}{l}\text { Social } \\
\text { distancing }\end{array}$ \\
\hline Hospital resource situation & $\begin{array}{l}\text { Diverted mainly to } \\
\text { COVID-19 cases }\end{array}$ & $\begin{array}{l}\text { Maintain ICU/HD bed } \\
\text { surge capacity } \\
\text { Conversion of some ORs } \\
\text { and wards to support } \\
\text { surgical workload } \\
\text { recovery } \\
\text { Accessibility and } \\
\text { capabilities for rapid } \\
\text { COVID-19 tests }\end{array}$ & $\begin{array}{l}\text { Scaling down } \\
\text { of ICU/HD bed } \\
\text { surge capacity } \\
\text { Progressive } \\
\text { reopening of } \\
\text { more ORs } \\
\text { Return of } \\
\text { redeployed } \\
\text { manpower }\end{array}$ & $\begin{array}{l}\text { Business as } \\
\text { usual }\end{array}$ & $\begin{array}{l}\text { Catch-up phase } \\
\text { Additional } \\
\text { resources for } \\
\text { make-up clinics, } \\
\text { extended hours } \\
\text { ORs }\end{array}$ \\
\hline \multicolumn{6}{|l|}{ Surgical services } \\
\hline $\begin{array}{l}\text { Overall clinical workload } \\
\text { (estimated) }\end{array}$ & $30 \% /$ essential cases only & $50-60 \%$ & $70-80 \%$ & $100 \%$ & $>100 \%$ \\
\hline Outpatient procedures & Only essential procedures & $\begin{array}{l}\text { Resume semi-urgent } \\
\text { procedures }\end{array}$ & $\begin{array}{l}\text { Ramp-up in } \\
\text { procedures, } \\
\text { including those } \\
\text { with more elective } \\
\text { indications }\end{array}$ & $100 \%$ & $>100 \%$ \\
\hline Operating rooms & Only essential surgeries & $\begin{array}{l}\text { Resume semi-urgent } \\
\text { surgeries, with emphasis } \\
\text { on short-stay surgeries } \\
\text { with less resource } \\
\text { consumption }\end{array}$ & $\begin{array}{l}\text { Ramp-up in } \\
\text { surgeries, } \\
\text { including those } \\
\text { with more elective } \\
\text { indications }\end{array}$ & $100 \%$ & $>100 \%$ \\
\hline
\end{tabular}

HD: high dependency; ICU: intensive care unit; OR: operating room 
the local prevailing conditions. Hospital availability is also described. There is a gradual increase in service provision from Phase 0 to Phase 4, and the proposed overall clinical workload, outpatient procedure workload, and operating room workload are described in Table 1. The table remains as a suggested guide for fellow surgeons worldwide. Its utilisation is the prerogative of the individual surgeon and institution, and needs to be adapted to local socio-economic and geo-political context.

\section{REFERENCES}

1. World Health Organization. Coronavirus disease (COVID-19) situation reports. Available at https://www.who.int/emergencies/diseases/novelcoronavirus-2019/situation-reports. Accessed on 27 July 2020.

2. Lim TK. The facts, fallacies and uncertainties about coronavirus disease 2019 (COVID-19). Ann Acad Med Singap 2020;49:343-5.

3. Hsu LY, Chia PY, Lim JF. The novel coronavirus (SARS-CoV-2) epidemic. Ann Acad Med Singap 2020;49:105-7.

4. Fu SJ, George EL, Maggio PM, et al. The consequences of delaying elective surgery: surgical perspective. Ann Surg 2020;272:e79-80.

5. Ho CS, Chee CY, Ho RC. Mental health strategies to combat the psychological impact of COVID-19 beyond paranoia and panic. Ann Acad Med Singap 2020;49:155-60.

6. American College of Surgeons. COVID-19: Elective case triage guidelines for surgical care. Available at https://www.facs.org/covid-19/ clinical-guidance/elective-case. Accessed on 27 July 2020.
7. Tan YQ, Wang Z, Tiong HY, et al. The START (Surgical Triage And Resource Allocation Tool) of surgical prioritization during the COVID-19 pandemic. Urology 2020;142:32-5.

8. Grenda TR, Whang S, Evans NR. Transitioning a surgery practice to telehealth during COVID-19. Ann Surg 2020;272:e168-9.

9. Shi AH, Guo W, Chng CK, et al. Precautions when providing dental care during coronavirus disease 2019 (COVID-19) pandemic. Ann Acad Med Singap 2020;49:312-9.

10. Tan JL, Tay VSL, Li H, et al. Otolaryngology surgery in time of COVID-19-what PPE to use when? Ann Acad Med Singap 2020; 49:387-92.

Yi Quan Tan, ${ }^{1} M B B S$, MRCS, Jirong $\underline{\mathrm{Lu}},{ }^{1} M B B S, M C I$, FAMS (Urology), Ziting Wang, ${ }^{1} M B B S, M C I, M R C S$,

Ho Yee Tiong, ${ }_{B M B S}$ (Hons), FAMS (Urology), ASTS,

Edmund Chiong, ${ }^{1,2}$ MBBS, PhD, FAMS (Urology)

${ }^{1}$ Department of Urology, National University Hospital, National University Health System, Singapore

${ }^{2}$ Department of Surgery, Yong Loo Lin School of Medicine, National University of Singapore, Singapore

Address for Correspondence: Dr Yi Quan Tan, Department of Urology, National University Hospital, National University Health System, Level 8, NUHS Tower Block, 1E Kent Ridge Road, Singapore 119228. Email: yi_quan_tan@nuhs.edu.sg 